MR ADAM STEARNS (Orcid ID : 0000-0003-4327-7360)

Article type : Original Article

CDI-00591-2019.R1

Original Article

\title{
Renal impairment after ileostomy formation: a frequent event
} with long term consequences

Alexandra Fielding MRCS [1,3] *, Rebecca Woods MRCS [1,3] *, Syed R. Moosvi FRCS [1], Richard

Q. Wharton MS FRCS $[1,2,3]$, Christopher T.M. Speakman MD FRCS $[1,2,3]$, Sandeep Kapur MD FRCS [1,3], Irshad Shaikh MD FRCS [1,2,3], James M. Hernon MD FRCS [1,2,3] Simon W. Lines PhD FRCP [4,5], Adam T. Stearns DPhil FRCS [1,2,3]

[1] Department of Colorectal Surgery, Norfolk \& Norwich University Hospitals NHS Foundation Trust, Colney Lane, Norwich. NR4 7UY.

[2] Norwich Medical School, University of East Anglia, Norwich, Norfolk.

This article has been accepted for publication and undergone full peer review but has not been through the copyediting, typesetting, pagination and proofreading process, which may lead to differences between this version and the Version of Record. Please cite this article as doi: 10.1111/CODI.14866

This article is protected by copyright. All rights reserved 
[3] Norwich Surgical Training and Research Academy, Level 3 Centre, Norfolk \& Norwich University Hospital, Colney Lane, Norwich. NR4 7UY

[4] Department of Nephrology, Norfolk \& Norwich University Hospitals NHS Foundation Trust, Colney Lane, Norwich. NR4 7UY.

[5] Department of Nephrology, St Bernard's Hospital, Harbour Views Rd, Gibraltar, Gibraltar. These authors contributed equally

This study was funded from departmental research funds. There are no conflicts of interest to declare for any author.

Corresponding author and address for reprints: Adam T Stearns, Dept of Colorectal Surgery, Norfolk \& Norwich University Hospitals NHS Foundation Trust, Colney Lane, Norwich. NR4 7UY. Tel: +441603287597_email: adam.stearns@nnuh.nhs.uk

Category of Paper: Original Article

Presented in Abstract form at The Association of Coloproctology of Great Britain \& Ireland, Birmingham, July 2018

Running Head: Renal impairment following rectal resection and ileostomy MeSH Terms: $\quad$ Ileostomy; Glomerular Filtration Rate; Rectal Neoplasms; Digestive System; Surgical Procedures; Renal Insufficiency

Word Count: 2994 words excluding title page, abstract, references, tables and figures

\section{What does this paper add to the literature?}

Dehydration is a common complication from ileostomy. However, the impact on renal function is poorly described. We demonstrate that ileostomy is an independent risk factor for postoperative renal impairment. This persists after ileostomy closure with a 2.2-fold increase in rates of new or worsening chronic kidney disease compared with patients without ileostomy.

This article is protected by copyright. All rights reserved 


\section{Abstract}

Aim: High stoma output and dehydration is common following ileostomy formation. However, the impact of this on renal function, both in the short term and after ileostomy reversal, remains poorly defined. We aimed to assess the independent impact on kidney function of an ileostomy after rectal cancer surgery, and subsequent reversibility after ileostomy closure.

Methods: This retrospective single-site cohort study identified patients undergoing rectal cancer resection from 2003-2017, with or without a diverting ileostomy. Renal function was calculated preoperatively, before ileostomy closure, and six months after ileostomy reversal (or matched times for patients without ileostomy). Demographics, oncological treatments, and nephrotoxic drug prescriptions were assessed. Outcome measures were deterioration from baseline renal function and development of moderate/ severe chronic kidney disease $(C K D \geq 3)$. Multivariate analysis was performed to assess independent risk factors for postoperative renal impairment.

Results: $\quad 583$ of 1213 patients had an ileostomy. Postoperative renal impairment occurred more frequently in ileostomates $(9.5 \%$ absolute increase in rate of $C K D \geq 3 ; P<0.0001)$ versus no change in patients without an ileostomy $(P=0.757)$. Multivariate analysis identified ileostomy formation, age, anastomotic leak and renin-angiotensin-system inhibitors as independently associated with postoperative renal decline. Despite stoma closure, ileostomates remained at increased risk of progression to new or worse CKD (74/438 [16.9\%]) compared to patients without an ileostomy (36/437 [8.2\%], P=0.0001, OR 2.264 [1.49 to 3.46$])$.

Conclusions: lleostomy formation is independently associated with kidney injury, with an increased risk persisting after stoma closure. Strategies to protect against kidney injury may be important in higher risk patients (elderly, receiving renin-angiotensin system antihypertensives, or following anastomotic leakage).

This article is protected by copyright. All rights reserved 


\section{Introduction}

Total mesorectal excision (TME) with sphincter-preservation is increasingly offered for rectal cancer resection[1]. However, a distal rectal anastomosis is accompanied by significant risk of leakage[2] associated with increased morbidity and mortality and adverse oncological outcomes[3-6]. A diverting stoma reduces the consequences of anastomotic leakage[7-12], with loop ileostomy widely advocated as a routine part of TME procedures[13].

A diverting loop ileostomy is itself associated with significant potential morbidity. Readmissions are common[14], with dehydration and electrolyte imbalance resulting from the high stoma output[15]; the cause in $40-43 \%$ of patients $[14,16-18]$. There have been few studies examining changes in renal function while an ileostomy is in situ[19-21]. Only one, a small study with limited controls, attempted to characterise the impact from ileostomy formation [21]. This study highlighted a 10-fold increase in readmissions with acute kidney injury for patients with an ileostomy in situ, but also an increased risk of developing severe chronic kidney disease (CKD stage 4) at twelve months. This was a diverse patient group, with a heterogenous control cohort, making it difficult to separate the impact of ileostomy on renal function versus adjuvant, neoadjuvant or palliative treatments.

Even transient impairments in renal function may impact on long-term outcomes. A temporary decline in renal function (particularly perioperatively) has been shown to be an independent prognostic predictor for the later development of CKD[22, 23]. Lower estimated glomerular filtration rate (eGFR) is associated with an increased risk of hospitalization, cardiovascular events, and death[24-26], with even small increases in serum creatinine having adverse prognostic significance[27].

This study set out to evaluate whether creation of an ileostomy is an independent risk factor for postoperative renal impairment after rectal resection, and to define the impact this may have on kidney function following ileostomy reversal.

This article is protected by copyright. All rights reserved 


\section{Methods}

\section{Patients}

This retrospective cohort study was performed at a single, high-volume, tertiary referral centre in the United Kingdom. Patients were identified from a prospectively-collected registry for all rectal cancer resections from January 2003 to March 2017. Patients undergoing elective rectal resection with primary anastomosis and formation of an ileostomy (total mesorectal excision and loop ileostomy: TME/LI) were identified along with comparison cohorts undergoing rectal resection without ileostomy: high anterior resection without ileostomy (HAR) or abdominoperineal excision of the rectum (APR). For the purposes of this study, patients were allocated to TME/LI or HAR based on the presence or absence of an ileostomy and were independent of tumour or anastomotic height. Exclusion criteria were: pathology other than rectal adenocarcinoma; sigmoid colonic cancer; patients undergoing extended, multivisceral or simultaneous segmental colonic resections; and patients undergoing surgery for recurrent rectal cancer. Patients undergoing Hartmann's procedure were specifically excluded as in our institution this is reserved for the frailest patients (too unfit for reconstruction or abdominoperineal resection) or for emergency resections. Patients undergoing neoadjuvant radiotherapy underwent either short-course preoperative radiotherapy (SCRT, 25Gy over five days) or long-course chemoradiotherapy (LCCRT, 45Gy over five weeks with a concomitant radiosensitizer), in keeping with contemporaneous guidelines. Neoadjuvant systemic chemotherapy and first-line adjuvant chemotherapy was 5-fluorouracil and oxaliplatin. Institutional and ethical approval was obtained (IRAS/REC reference 18/NI/0138; University of East Anglia Faculty of Medicine and Health Sciences REC 2017/18-90SE).

\section{Data Collection}

Demographic and postoperative care data were retrieved from electronic notes and databases, and included anastomotic leakage, returns to theatre, and discharge medications (non-steroidal antiinflammatory drugs, anti-hypertensives, metformin and other antidiabetic medications, proton-pump inhibitors). Antidiabetic and antihypertensive medications were used as surrogate markers of diabetes mellitus and hypertension respectively. Chemotherapy or radiotherapy regimens were recorded, as were unplanned readmissions within a year postoperatively.

This article is protected by copyright. All rights reserved 


\section{Renal function}

Serum creatinine levels were extracted from routine blood tests taken in outpatient clinics or primary care; in-patient results were excluded. Preoperative blood tests were used as a baseline $\left(T_{0}\right)$. For patients undergoing neoadjuvant chemo(radio)therapy, these were taken after completion of neoadjuvant therapy. For $\mathrm{TME} / \mathrm{LI}$ patients who underwent ileostomy closure, serum creatinine was abstracted immediately prior to ileostomy closure $\left(\mathrm{T}_{1}\right)$. Pilot data suggested median time to ileostomy closure was approximately six months after rectal resection[28]. Therefore, for comparison in HAR and APR patients (and TME/LI patients who did not undergo ileostomy closure), $\mathrm{T}_{1}$ was taken as 6-months after rectal resection, coinciding with routine surveillance blood tests. Results were included in analysis when they fell within three months of the calculated follow-up dates (preoperatively for baseline or before ileostomy closure). Finally, follow-up renal function $\left(T_{2}\right)$ was assessed 6-months following ileostomy closure (TME/LI) or 12-months after rectal resection (HAR and APR) respectively.

Estimated glomerular filtration rate (eGFR) was calculated de novo from creatinine assay results using the CKI-EPI (Chronic Kidney Disease Epidemiology Study) equation[29-32], as earlier cohorts used different equations for estimating eGFR. CKD stage was graded by Kidney Disease Improving Global Outcomes 2012 guidelines[30-32] [CKD stage 3 (CKD3) eGFR 30 to $<60 \mathrm{~mL}$.min.1.73m²; CKD4 15 to



\section{Outcomes}

The main outcome measure was absolute change in eGFR at postoperative timepoint $T_{1}$ compared to the preoperative $\left(T_{0}\right)$ baseline. Secondary outcomes were long-term development of moderate/ severe CKD

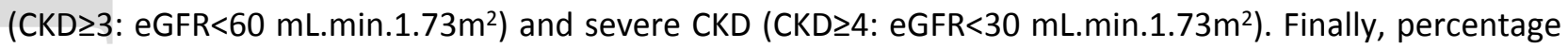
changes in eGFR between $T_{0}$ and $T_{1}$ were assessed, as trajectory is increasingly recognised as an important marker of long-term outcome[33-36]. Pilot studies demonstrated that approximately one-fifth of patients had a deterioration of greater than $20 \%\left(\mathrm{eGFR}_{-20 \%}\right)$ from preoperative baseline[28] and this was therefore taken as a threshold for most severe postoperative renal impairment as a method of converting continuous data to categorical data.

\section{Statistics}

This article is protected by copyright. All rights reserved 
For simple descriptive statistics between cohorts, t-tests and chi-squared tests or one-way ANOVA were used. For initial assessments of the impact of ileostomycreation on changes in postoperative eGFR, univariate and then multivariate regression analysis was performed. Absolute changes in eGFR were used as the dependent variable. For multivariate regression analysis, all factors with $\mathrm{P}<0.2$ on univariate analysis were included.

Statistical analysis was performed using Stata 12.1 (StataCorp, Texas, USA), and graphical data presented using GraphPad Prism 7 (La Jolla, CA). Statistical significance was taken as $\mathrm{P}<0.05$.

This article is protected by copyright. All rights reserved 


\section{Results}

Patient demographics

1213 patients were included in this study. 753 (62.1\%) were male and the median age was 69.4 years (range 24.5-91.1). 583 (48.1\%) patients had a loop ileostomy fashioned as part of the primary procedure (TME/LI), while 630 had no ileostomy formed (HAR: 364 patients and APR: 266 patients). No patient underwent defunctioning colostomy. Patient characteristics differed between cohorts, with the TME/LI cohort composed of younger patients $(P<0.001)$ and more males $(67.9 \%, P<0.001)$. There were differences in preoperative (baseline) renal function $(P=0.002)$, with a lower proportion of patients with $C K D \geq 3$ undergoing TME/LI surgery (13.4\%) compared to those undergoing HAR or APR (19.0\%). There were subtle differences in tumour stage, with a lower proportion of Dukes B (stage II) tumours in patients undergoing TME/LI. Patients undergoing APR had a higher rate of node-negative disease compared with TME/LI and HAR (73.7\% versus $63.6 \%$ and $61.8 \%, P=0.001)$, which may be as a consequence of higher rates of prior neoadjuvant (chemo)radiotherapy. Anastomotic leak rates were higher after TME/LI (11.0\%) compared to HAR (5.2\%, P=0.002). The demographic data are summarised in Table 1.

\section{Ileostomy Closure}

lleostomy closure was performed in 494 of 583 patients (84.7\%), with a further three patients (excluded from further analysis) undergoing closure at another institution on an unknown date. The remaining 86 patients were censored due to death (56 patients) or end of follow-up (30 patients) to 1st July 2018. 50\% of all TME/LI patients underwent closure by 217 days post-operatively, with $77.9 \%$ closure at 1 year postoperatively (Figure 1). For those patients who did undergo closure, median time to closure was 189 days (mean 227 days, interquartile range 119 to 291 days).

\section{Readmissions}

Data on unplanned or emergency readmissions within one year of rectal resection were available in $869 / 1213$ patients (data unavailable prior to 2007). 226/869 (26.0\%) patients had any unplanned readmission within a year of surgery. 134/426 (31.5\%) patients undergoing ileostomy formation underwent at least one unplanned readmission in the year after surgery compared to 92/443 (20.8\%) patients without ileostomy ( $P=0.0004$, OR 1.75 [1.29-2.37]). Subgroup analysis of patients without ileostomy showed readmission was more common following APR (48/177 [27.1\%]; P=0.330 vs TME/LI 
cohort) rather than HAR (44/266 [16.5\%]; P<0.0001). Many patients experienced multiple readmissions, and mean number of readmissions was 0.47 readmissions per patient for TME/LI versus 0.21 and 0.39 for HAR and APR respectively.

\section{Impact of ileostomy on postoperative renal function and chronic kidney disease}

Renal function data were available to calculate both preoperative $\left(T_{0}\right)$ and postoperative $\left(T_{1}\right)$ eGFR for 1058 (87.2\%) patients (TME/LI 561 patients; HAR 288; APR 209). The median time interval between $T_{0}$ and $\mathrm{T}_{1}$ was 182 days with no difference between the three cohorts $(\mathrm{P}=0.523)$.

There was a significant postoperative decline in eGFR in ileostomates between $T_{0}$ and $T_{1}(78.3 \pm 0.68$ vs $73.9 \pm 0.83 \mathrm{~mL} \cdot \min .1 .73 \mathrm{~m}^{2} ; \mathrm{P}<0.0001$ paired $\mathrm{t}$-test). No such decline was seen in patients without ileostomy or on subgroup analysis of HAR or APR patients $(P>0.401)$. There was also a significant postoperative increase in proportion of patients with CKD $\geq 3$ (Table 2, $13.4 \%$ to $23.0 \%, P<0.0001$ ), again, not observed in patients without ileostomy (18.8\% to $17.9 \%, \mathrm{P}=0.757)$, including subgroup analysis of $\mathrm{HAR}$ and APR patients $(P \geq 0.620)$. Similarly, presence of ileostomy increased incidence of post-operative severe $C K D(C K D \geq 4)$ by 12.7 -fold $(P=0.0012)$, as compared to no change following rectal resection without ileostomy $(P>0.999)$.

Clinically significant declines from baseline renal function $\left(\Delta \mathrm{eGFR}_{-20 \%}\right)$ were more frequently observed in patients with ileostomy, occurring in 97/561 (17.3\%) compared 32/497 (6.4\%) patients without ileostomy $(P<0.0001)$. The odds ratio of $\Delta \mathrm{eGFR}_{-20 \%}$ after ileostomy was 3.04 (1.99-4.69) versus patients without an ileostomy $(P<0.0001)$. There was no difference between APR and HAR $(P=0.460)$.

\section{Risk factors for development of postoperative renal impairment}

Univariate analysis identified increased age, higher preoperative eGFR, ileostomy formation and anastomotic leakage as correlated with absolute decline in eGFR at $T_{1}$ compared to preoperative $\left(T_{0}\right)$ baseline (Table 3, $\mathrm{P}<0.001$ ). ASA grade and prescription of renin-angiotensin system inhibitors on discharge were also correlated with a post-operative decline in eGFR at $T_{1}(P<0.05)$. Adjuvant chemotherapy was associated on univariate analysis with a post-operative improvement in eGFR $(P=0.001)$.

In multivariate analysis, ileostomy formation remained independently associated with decline in eGFR, contributing an absolute $5.3 \mathrm{~mL} \cdot \mathrm{min}^{-1} .1 .73 \mathrm{~m}^{2}$ decline in eGFR ( $\mathrm{P}<0.001$, Table 3$)$. Increased age, higher 
preoperative eGFR, postoperative anastomotic leak and renin-angiotensin system were also independently associated with an absolute postoperative decline in eGFR $(P<0.05)$. As there was a relatively high proportion of missing data for discharge medications (707 patients included in multivariate analysis), analysis was repeated excluding drugs from the multivariate analysis (926 patients included). This did not change the variables independently associated with postoperative renal impairment. Adjuvant chemotherapy was not associated with post-operative changes in eGFR on multivariate analysis, suggesting this represented confounding biases from other variables.

\section{Impact of postoperative renal impairment on long-term renal function}

Blood tests were available at both $T_{0}$ and $T_{2}$ in 875 patients, with $T_{2}$ a median of 383 days after original surgery. In patients who previously had an ileostomy, there was an absolute increase of $14.9 \%$ in rates of CKD $\geq 3$ (Table 2, $28.4 \%$ versus $13.4 \%$ preoperatively), compared to an absolute increase of $7.0 \%$ in patients who had never had an ileostomy. When considering changes in CKD stage, 74/438 (16.9\%) of patients previously undergoing ileostomy formation developed new CKD or progressed to a worse CKD stage, compared to $36 / 437(8.2 \%)$ in patients who had never had ileostomy ( $P=0.0001, O R 2.264$ [1.49 to $3.46])$.

The impact on long-term renal function, of a decline $>20 \%$ in baseline renal function at $\mathrm{T}_{1}\left(\Delta \mathrm{eGFR}_{-20 \%}\right)$, was assessed in 818 patients where data were available for all three time-points. These patients were particularly at risk of developing moderate or severe CKD: risk of CKD $\geq 3$ at $T_{2}$ was significantly increased (OR 6.89 [4.44-10.8], $\mathrm{P}<0.0001$ ) in patients who previously experienced $>20 \%$ decline in baseline renal function, while risk of severe CKD ( $C K D \geq 4)$ was also significantly increased (OR 7.44 [2.74-20.1], $P=0.0003$ ).

This article is protected by copyright. All rights reserved 


\section{Discussion}

In this study, we confirmed that ileostomy formation was independently associated with postoperative renal impairment after rectal resection. Other independent risk factors included increasing age, anastomotic leakage and prescription of renin-angiotensin system-inhibitors. Adjuvant chemotherapy was associated with postoperative improvements in eGFR. This was only seen on univariate (not multivariate) analysis, and therefore is likely to be due to other biases. It may further be a marker of patient selection, and of closer post-operative monitoring with admissions or fluid therapy in cases with evidence of renal impairment. While on crude analysis of mean eGFR data, this may appear to be a trivial decrease in eGFR (mean $4.4 \mathrm{~mL} \cdot \mathrm{min}^{-1} .1 .73 \mathrm{~m}^{2}$ ), it belies a very significant decrease in eGFR ( $>20 \%$ decline from baseline) in approximately one-fifth of patients undergoing ileostomy formation. This renal impairment persists following ileostomy closure, with subsequent development of moderate or severe CKD in $61 \%$ of such patients.

While these modest declines in renal function may seem of little clinical significance to the practicing colorectal surgeon, even small declines in kidney function have marked effect on long-term outcomes, particularly cardiovascular mortality[24, 37-39]. Longitudinal population studies have demonstrated patients with CKD3b (eGFR 30-44mL.min.1.73 $\mathrm{m}^{2}$ ) have a 1.8-fold increase in all-cause mortality compared to patients with eGFR $>60 \mathrm{~mL}$. $\mathrm{min} .1 .73 \mathrm{~m}^{2}$, while for CKD4 and CKD5 patients this increases to 3.2- and 5.9fold respectively[24]. Risk is not confined to patients with established CKD: differences in renal function even within the bounds of 'normal' kidney function influence cardiovascular mortality with a 2.6-fold increase in patients with eGFR $60-75 \mathrm{~mL} \cdot \mathrm{min} .1 .73 \mathrm{~m}^{2}$ compared to patients with eGFR $>104 \mathrm{~mL} . \mathrm{min} .1 .73 \mathrm{~m}^{2}[40]$. Strategies such as electrolyte drinks, which have been demonstrated to prevent renal impairment following ileostomy formation, should now be evaluated further to assess impact on short-term and late renal function[41].

Although complications from ileostomy (particularly high-output stomas) have long been recognised clinically, this is poorly described in the literature. We confirm increased readmissions following ileostomy formation compared to resections without loop ileostomy. We found similar rates of readmission following abdominoperineal resection compared to rectal resections with ileostomy. While an analysis of the cause of readmission is beyond the scope of this paper, readmissions following APR are likely largely due to perineal wound complications[42], as compared to readmissions following ileostomy formation

This article is protected by copyright. All rights reserved 
where dehydration is the leading aetiology[16]. Any complications in the early postoperative period (particularly readmissions or renal impairment) may influence rectal cancer outcomes, through delays leading to early abandonment of, or not starting, adjuvant chemotherapy regimes[43-45].

There are few previous studies which define the impact of ileostomy formation on postoperative renal function. One previous report described a cohort of ileostomates, noting a post-operative mean eGFR decline of $6 \mathrm{~mL} . \mathrm{min} .1 .73 \mathrm{~m}^{2}$, comparable to our population[19]. However, as a single cohort of mixed pathologies, it could not differentiate ileostomy-related renal impairment from other causes such as adjuvant chemotherapy or inflammatory bowel disease. A second study, using propensity-matching in a small cohort to demonstrate the effect of ileostomy formation, was strongly associated with renal impairment and subsequent progression to CKD4[21]. However, this study was limited by a high rate of surgery for palliation in the ileostomy cohort and a near-exclusively male population.

These limitations are highlighted by the differences observed here in demographics, tumour and treatment factors observed between cohorts. Significant (albeit small) differences were observed in preoperative eGFR, with better preoperative renal function seen in patients undergoing rectal resection with ileostomy compared to HAR or APR. These latter cohorts had significantly more patients with preoperative moderate or severe CKD. This likely reflects surgeon decision-making in that patients with advanced comorbidity, or patients with a distal cancer, may be treated with an APR rather than undergo a low pelvic anastomosis. There were significant differences in neoadjuvant treatment between cohorts: disease stage is likely to have influenced both neoadjuvant therapy and in turn the surgical procedure. Furthermore, perception that neoadjuvant chemoradiotherapy increases anastomotic leakage makes ileostomy formation more likely. Distal tumours are at an increased risk of circumferential margin encroachment, and therefore more likely to receive neoadjuvant chemoradiotherapy. Irradiation of the sphincters is a relative contraindication to sphincter-preservation, and such patients may be offered APR rather than reconstruction. Age, gender, previous sphincter injury or incontinence, and perceived risk of subsequent development of systemic disease, may all influence surgeon decision-making regarding reconstruction versus APR. We noted significantly earlier pathological disease stage in patients undergoing APR rather than TME/LI, which may reflect the higher rates of neoadjuvant treatments. Anastomotic leakage was more frequent in the ileostomy cohort than in the non-ileostomy cohort, and although this was addressed by multivariate analysis, it is possible that the contribution from ileostomy

This article is protected by copyright. All rights reserved 
has been overestimated. Conversely, pelvic or perineal sepsis is common after APR and has not been accounted in this study.

A few aspects of the methodology require comment. The use of a threshold $20 \%$ decline in renal function as an endpoint reflects increasing calls to adopt such a strategy[33, 34] and is in keeping with previous studies[35, 36]. Percentage change based on single sample assays at each time-point is less precise than multiple measures, while lack of urinary albumin data limit interpretation of CKD states. Ideally, renal function at any time point should be assessed on two consecutive samples, but not feasible in such a retrospective cohort study. This would exclude the possibility that a significant decline in renal function was due to an erroneous pre- or post-operative eGFR estimate. The former seems unlikely as there was no difference in pre-operative eGFR between patients who did or did not subsequently develop renal impairment. Any estimate of eGFR from serum creatinine is subject to errors. CKI-EPI equation performs better than the Modification of Diet in Renal Disease Study (MDRD) equation in predicting mortality and end-stage renal disease[46, 47]. Changes in body mass composition, particularly in patients undergoing major catabolic and functional changes (for example, following anastomotic leakage), may influence creatinine levels and therefore eGFR. As patients in the ileostomy cohort are more likely to have anastomotic leakage, this may be a source of bias. However, in most patients, body composition would be expected to have normalised at six-months post-operatively. Furthermore, post-operative muscle loss would tend to overestimate eGFR by reducing creatinine, reducing apparent postoperative renal impairment. Finally, although we are not aware of changes in the laboratory creatinine assay, it is possible this has happened over the extended study period. As each post-operative blood tests are related to preoperative tests, only a very small number of patients (in both ileostomy and no ileostomy cohorts) would be affected.

Data on the height of the tumour and of the colorectal anastomosis were not collected; all sphincterpreserving rectal resections where an ileostomy was formed were allocated as TME/LI cases. Patients were prospectively recorded on institutional databases as being either rectal or sigmoid cancer, and the latter excluded on that basis. While there may have been some errors in coding, with some proximal rectal cancers recorded as sigmoid cancers, or vice versa, it is unlikely that inclusion of a small number of distal sigmoid cancers in this dataset would to be a significant confounding factor with regards renal function outcome measures. We similarly do not have data on use of ureteric stents, although these would only routinely be used for extended resections (excluded from the analysis).

This article is protected by copyright. All rights reserved 
Our cohort is noteworthy by the lack of ethnic diversity, reflecting the local demographic. The incidence of renal injury following cardiac surgery appears to differ among ethnic groups[48]; whether this is the case for patients undergoing rectal cancer surgery is unknown. One should bear this in mind when generalizing the results from this study to non-Caucasian or mixed ethnicity populations. Finally, while most patients will have received mechanical bowel preparation prior to colonoscopic evaluation, patients undergoing planned TME/LI would routinely be prescribed a second, pre-operative mechanical bowel preparation, while those undergoing APR or HAR may not, with an enema used in some circumstances. This could be viewed as an independent cause of the renal impairment, rather than the ileostomy. However, previous studies, including a report from our own institution, have not consistently demonstrated bowel preparation is associated with renal impairment [49-51]. Many of these issues are inherent problems in a retrospective single-centre study covering an extended time period, and, as such, these findings need validation in a multicentre prospective setting.

In summary, this study demonstrates that ileostomy formation is independently associated with kidney injury occurring while the ileostomy is in situ. This kidney injury persists with long-term follow-up, even after ileostomy reversal. This highlights that ileostomy formation is not without risk, and that the thresholds for forming an ileostomy should be set accordingly, especially in lower-risk left-sided anastomoses. Impact on renal function has not been considered in recent trials evaluating early ileostomy closure but may be an additional benefit[52]. Careful monitoring of renal function in the post-operative period (particularly in higher risk patients such as older patients and those taking renin-angiotensin system-inhibitors) may allow earlier identification of kidney injury, and the opportunity to implement intervention such as oral rehydration salts [41] or prioritising early closure.

This article is protected by copyright. All rights reserved 


\section{References}

1. Warschkow R, Ebinger SM, Brunner W, Schmied BM, Marti L. Survival after Abdominoperineal and Sphincter-Preserving Resection in Nonmetastatic Rectal Cancer: A Population-Based Time-Trend and Propensity Score-Matched SEER Analysis. Gastroenterol Res Pract 2017; 2017: 6058907. Snijders HS, Wouters MW, van Leersum NJ, Kolfschoten NE, Henneman D, de Vries AC, et al. Meta-analysis of the risk for anastomotic leakage, the postoperative mortality caused by leakage in relation to the overall postoperative mortality. Eur J Surg Oncol 2012; 38: 1013-9.

3. den Dulk M, Smit M, Peeters KC, Kranenbarg EM, Rutten HJ, Wiggers T, et al. A multivariate analysis of limiting factors for stoma reversal in patients with rectal cancer entered into the total mesorectal excision (TME) trial: a retrospective study. Lancet Oncol 2007; 8: 297-303.

4. Law WL, Choi HK, Lee YM, Ho JW. The impact of postoperative complications on long-term outcomes following curative resection for colorectal cancer. Ann Surg Oncol 2007; 14: 2559-66.

5. Matthiessen P, Hallbook O, Rutegard J, Sjodahl R. Population-based study of risk factors for postoperative death after anterior resection of the rectum. Br J Surg 2006; 93: 498-503.

6. Wang S, Liu J, Wang S, Zhao H, Ge S, Wang W. Adverse Effects of Anastomotic Leakage on Local Recurrence and Survival After Curative Anterior Resection for Rectal Cancer: A Systematic Review and Meta-analysis. World J Surg 2017; 41: 277-84.

7. Huser N, Michalski CW, Erkan M, Schuster T, Rosenberg R, Kleeff J, et al. Systematic review and meta-analysis of the role of defunctioning stoma in low rectal cancer surgery. Ann Surg 2008; 248: 52-60.

8. Gu WL, Wu SW. Meta-analysis of defunctioning stoma in low anterior resection with total mesorectal excision for rectal cancer: evidence based on thirteen studies. World J Surg Oncol 2015; 13: 9.

9. Chen J, Wang DR, Yu HF, Zhao ZK, Wang LH, Li YK. Defunctioning stoma in low anterior resection for rectal cancer: a meta- analysis of five recent studies. Hepatogastroenterology 2012; 59: 182831.

10. Matthiessen P, Hallbook O, Rutegard J, Simert G, Sjodahl R. Defunctioning stoma reduces symptomatic anastomotic leakage after low anterior resection of the rectum for cancer: a randomized multicenter trial. Ann Surg 2007; 246: 207-14.

11. Tan WS, Tang CL, Shi L, Eu KW. Meta-analysis of defunctioning stomas in low anterior resection for rectal cancer. Br J Surg 2009; 96: 462-72.

This article is protected by copyright. All rights reserved 
12. Wu SW, Ma CC, Yang Y. Role of protective stoma in low anterior resection for rectal cancer: a meta-analysis. World J Gastroenterol 2014; 20: 18031-7.

13. Monson JR, Weiser MR, Buie WD, Chang GJ, Rafferty JF, Buie WD, et al. Practice parameters for the management of rectal cancer (revised). Dis Colon Rectum 2013; 56: 535-50.

14. Akesson $\mathrm{O}$, Syk I, Lindmark G, Buchwald P. Morbidity related to defunctioning loop ileostomy in low anterior resection. Int J Colorectal Dis 2012; 27: 1619-23.

15. Clarke AM, Chirnside A, Hill GL, Pope G, Stewart MK. Chronic dehydration and sodium depletion in patients with established ileostomies. Lancet 1967; 2: 740-3.

16. Fish DR, Mancuso CA, Garcia-Aguilar JE, Lee SW, Nash GM, Sonoda T, et al. Readmission After Ileostomy Creation: Retrospective Review of a Common and Significant Event. Ann Surg 2017; 265: 379-87.

17. Messaris E, Sehgal R, Deiling S, Koltun WA, Stewart D, McKenna K, et al. Dehydration Is the Most Common Indication for Readmission After Diverting Ileostomy Creation. Diseases of the Colon \& Rectum 2012; 55: 175-80.

18. Hayden DM, Pinzon MC, Francescatti AB, Edquist SC, Malczewski MR, Jolley JM, et al. Hospital readmission for fluid and electrolyte abnormalities following ileostomy construction: preventable or unpredictable? J Gastrointest Surg 2013; 17: 298-303.

19. Gessler B, Haglind E, Angenete E. A temporary loop ileostomy affects renal function. Int J Colorectal Dis 2014; 29: 1131-5.

20. Beck-Kaltenbach N, Voigt K, Rumstadt B. Renal impairment caused by temporary loop ileostomy. Int J Colorectal Dis; 26: 623-6.

21. Li L, Lau KS, Ramanathan V, Orcutt ST, Sansgiry S, Albo D, et al. lleostomy creation in colorectal cancer surgery: risk of acute kidney injury and chronic kidney disease. J Surg Res 2017; 210: 20412. Ishani A, Xue JL, Himmelfarb J, Eggers PW, Kimmel PL, Molitoris BA, et al. Acute kidney injury increases risk of ESRD among elderly. J Am Soc Nephrol 2009; 20: 223-8.

23. van Kuijk JP, Flu WJ, Chonchol M, Hoeks SE, Winkel TA, Verhagen HJ, et al. Temporary perioperative decline of renal function is an independent predictor for chronic kidney disease. Clin J Am Soc Nephrol 2010; 5: 1198-204.

24. Go AS, Chertow GM, Fan D, McCulloch CE, Hsu CY. Chronic kidney disease and the risks of death, cardiovascular events, and hospitalization. N Engl J Med 2004; 351: 1296-305.

25. Go AS, Yang J, Ackerson LM, Lepper K, Robbins S, Massie BM, et al. Hemoglobin level, chronic kidney disease, and the risks of death and hospitalization in adults with chronic heart failure: the 
Anemia in Chronic Heart Failure: Outcomes and Resource Utilization (ANCHOR) Study. Circulation 2006; 113: 2713-23.

26. Chronic Kidney Disease Prognosis C, Matsushita K, van der Velde M, Astor BC, Woodward M, Levey AS, et al. Association of estimated glomerular filtration rate and albuminuria with all-cause and cardiovascular mortality in general population cohorts: a collaborative meta-analysis. Lancet 2010; 375: 2073-81.

27. Forman DE, Butler J, Wang Y, Abraham WT, O'Connor CM, Gottlieb SS, et al. Incidence, predictors at admission, and impact of worsening renal function among patients hospitalized with heart failure. J Am Coll Cardiol 2004; 43: 61-7.

28. Woods R, Fielding A, Moosvi SR, Wharton R, Shaikh I, Hernon J, et al. Ileostomy is associated with chronically impaired renal function after rectal cancer surgery. Colorectal Dis 2017; 19: 32.

29. Levey AS, Stevens LA, Schmid CH, Zhang YL, Castro AF, 3rd, Feldman HI, et al. A new equation to estimate glomerular filtration rate. Ann Intern Med 2009; 150: 604-12.

30. Kidney Disease: Improving Global Outcomes Chronic Kidney Disease Guideline Development Work Group M. KDIGO 2012 Clinical Practice Guideline for the Evaluation and Management of Chronic Kidney Disease. Chapter 1: Definition and classification of CKD Kidney Int Supp/ 2013; 3: 19-62.

31. Stevens PE, Levin A, Kidney Disease: Improving Global Outcomes Chronic Kidney Disease Guideline Development Work Group M. Evaluation and management of chronic kidney disease: synopsis of the kidney disease: improving global outcomes 2012 clinical practice guideline. Ann Intern Med 2013; 158: 825-30.

32. Andrassy KM. Comments on 'KDIGO 2012 Clinical Practice Guideline for the Evaluation and Management of Chronic Kidney Disease'. Kidney Int 2013; 84: 622-3.

33. Rosansky SJ, Glassock RJ. Is a decline in estimated GFR an appropriate surrogate end point for renoprotection drug trials? Kidney Int 2014; 85: 723-7.

34. Coresh J, Turin TC, Matsushita K, Sang Y, Ballew SH, Appel LJ, et al. Decline in estimated glomerular filtration rate and subsequent risk of end-stage renal disease and mortality. JAMA 2014; 311: 2518-31.

35. Cheng TY, Wen SF, Astor BC, Tao XG, Samet JM, Wen CP. Mortality risks for all causes and cardiovascular diseases and reduced GFR in a middle-aged working population in Taiwan. Am J Kidney Dis 2008; 52: 1051-60.

36. Chen YC, Weng SC, Liu JS, Chuang HL, Hsu CC, Tarng DC. Severe Decline of Estimated Glomerular Filtration Rate Associates with Progressive Cognitive Deterioration in the Elderly: A CommunityBased Cohort Study. Sci Rep 2017; 7: 42690.

This article is protected by copyright. All rights reserved 
37. Vanholder R, Massy Z, Argiles A, Spasovski G, Verbeke F, Lameire N, et al. Chronic kidney disease as cause of cardiovascular morbidity and mortality. Nephrol Dial Transplant 2005; 20: 1048-56.

38. Beddhu S, Allen-Brady K, Cheung AK, Horne BD, Bair T, Muhlestein JB, et al. Impact of renal failure on the risk of myocardial infarction and death. Kidney Int 2002; 62: 1776-83.

39. Fried LF, Shlipak MG, Crump C, Bleyer AJ, Gottdiener JS, Kronmal RA, et al. Renal insufficiency as a predictor of cardiovascular outcomes and mortality in elderly individuals. J Am Coll Cardiol 2003; 41: $1364-72$.

40. Van Biesen W, De Bacquer D, Verbeke F, Delanghe J, Lameire N, Vanholder R. The glomerular filtration rate in an apparently healthy population and its relation with cardiovascular mortality during 10 years. Eur Heart J 2007; 28: 478-83.

41. Migdanis A, Koukoulis G, Mamaloudis I, Baloyiannis I, Migdanis I, Kanaki M, et al. Administration of an Oral Hydration Solution Prevents Electrolyte and Fluid Disturbances and Reduces Readmissions in Patients With a Diverting lleostomy After Colorectal Surgery: A Prospective, Randomized, Controlled Trial. Dis Colon Rectum 2018; 61: 840-6.

42. Wiatrek RL, Thomas JS, Papaconstantinou HT. Perineal wound complications after abdominoperineal resection. Clin Colon Rectal Surg 2008; 21: 76-85.

43. Phatak UR, Kao LS, You YN, Rodriguez-Bigas MA, Skibber JM, Feig BW, et al. Impact of ileostomyrelated complications on the multidisciplinary treatment of rectal cancer. Ann Surg Oncol 2014; 21: $507-12$.

44. Turner MC, Farrow NE, Rhodin KE, Sun Z, Adam MA, Mantyh CR, et al. Delay in Adjuvant Chemotherapy and Survival Advantage in Stage III Colon Cancer. J Am Coll Surg 2018; 226: 670-8.

45. Biagi JJ, Raphael MJ, Mackillop WJ, Kong W, King WD, Booth CM. Association between time to initiation of adjuvant chemotherapy and survival in colorectal cancer: a systematic review and meta-analysis. JAMA 2011; 305: 2335-42.

46. Matsushita K, Mahmoodi BK, Woodward M, Emberson JR, Jafar TH, Jee SH, et al. Comparison of risk prediction using the CKD-EPI equation and the MDRD study equation for estimated glomerular filtration rate. JAMA 2012; 307: 1941-51.

47. Matsushita K, Tonelli M, Lloyd A, Levey AS, Coresh J, Hemmelgarn BR, et al. Clinical risk implications of the CKD Epidemiology Collaboration (CKD-EPI) equation compared with the Modification of Diet in Renal Disease (MDRD) Study equation for estimated GFR. Am J Kidney Dis 2012; 60: 241-9.

48. Chew ST, Mar WM, Ti LK. Association of ethnicity and acute kidney injury after cardiac surgery in a South East Asian population. Br J Anaesth 2013; 110: 397-401.

This article is protected by copyright. All rights reserved 
49. Singal AK, Rosman AS, Post JB, Bauman WA, Spungen AM, Korsten MA. The renal safety of bowel preparations for colonoscopy: a comparative study of oral sodium phosphate solution and polyethylene glycol. Aliment Pharmacol Ther 2008; 27: 41-7.

50. Khurana A, McLean L, Atkinson S, Foulks CJ. The effect of oral sodium phosphate drug products on renal function in adults undergoing bowel endoscopy. Arch Intern Med 2008; 168: 593-7.

51. Al-Naeeb YT, Bowzyk Y, Tighe R. PP-002 Effect of administering Picolax prior to colonoscopy on renal function, electrolytes and magnesium in all patients in a gastroenterology day unit Gut 2010; 59: A40-1.

52. Danielsen AK, Park J, Jansen JE, Bock D, Skullman S, Wedin A, et al. Early Closure of a Temporary lleostomy in Patients With Rectal Cancer: A Multicenter Randomized Controlled Trial. Ann Surg 2017; 265: 284-90.

This article is protected by copyright. All rights reserved 


\begin{tabular}{|c|c|c|c|c|c|c|}
\hline & $\begin{array}{l}\text { Ileostomy } \\
\qquad n=583\end{array}$ & $\begin{array}{l}\text { No lleostomy } \\
\qquad n=630\end{array}$ & $\begin{array}{l}\text { Total } \\
n=1213\end{array}$ & $\mathbf{P}$ & $\begin{array}{c}\text { "No lleoston } \\
\text { HAR } \\
n=364\end{array}$ & $\begin{array}{c}\text { APR } \\
\text { AProups } \\
n=266\end{array}$ \\
\hline $\begin{array}{l}\text { Median Age } \\
\text { (Interquartile Range) }\end{array}$ & $67 \cdot 7(61 \cdot 0-74 \cdot 1)$ & $70.9(62.5-77.9)$ & $69 \cdot 4(61 \cdot 8-75 \cdot 9)$ & $<0.0001$ & $71 \cdot 0(62 \cdot 2-78 \cdot 1)$ & $70 \cdot 9(63 \cdot 9-77 \cdot 8)$ \\
\hline Male sex (\%) & $396(67 \cdot 9)$ & $357(56.7)$ & $753(62 \cdot 1)$ & $<0.0001$ & $204(56 \cdot 0)$ & $153(57 \cdot 5)$ \\
\hline Preoperative eGFR \pm S.D. & $78 \cdot 2 \pm 17.1$ & $75.2 \pm 16.1$ & $76 \cdot 6 \pm 16.7$ & 0.002 & $74 \cdot 9 \pm 17.3$ & $75 \cdot 6 \pm 16.9$ \\
\hline $\begin{array}{l}\text { ASA Grade (\%) } \\
1 \\
2 \\
3 \\
4 \\
\text { Not recorded } \\
\end{array}$ & $\begin{array}{c}71(12 \cdot 2) \\
370(63 \cdot 5) \\
74(12 \cdot 7) \\
2(0 \cdot 3) \\
66(11 \cdot 3) \\
\end{array}$ & $\begin{array}{c}66(10.5) \\
374(59.4) \\
101(16.0) \\
4(0.6) \\
85(13.5) \\
\end{array}$ & $\begin{array}{c}137(11 \cdot 3) \\
744(61 \cdot 3) \\
175(14 \cdot 4) \\
6(0 \cdot 5) \\
151(12 \cdot 5) \\
\end{array}$ & 0.231 & $\begin{array}{c}44(12 \cdot 1) \\
213(58 \cdot 5) \\
57(15 \cdot 7) \\
2(0 \cdot 6) \\
48(13 \cdot 2) \\
\end{array}$ & $\begin{array}{c}22(8 \cdot 3) \\
161(60 \cdot 5) \\
44(16 \cdot 5) \\
2(0 \cdot 8) \\
37(13 \cdot 9) \\
\end{array}$ \\
\hline $\begin{array}{l}\text { Tumour Dukes' stage (\%) } \\
\text { A [pTO-2 NO] } \\
\text { В [pT3-4 NO] } \\
\text { C [pT0-4 N1+] }\end{array}$ & $\begin{array}{l}207(35 \cdot 5) \\
164(28 \cdot 1) \\
212(36 \cdot 4) \\
\end{array}$ & $\begin{array}{l}198(31.4) \\
223(35.4) \\
209(33.2) \\
\end{array}$ & $\begin{array}{l}405(33 \cdot 4) \\
387(31 \cdot 9) \\
421(34 \cdot 7) \\
\end{array}$ & 0.025 & $\begin{array}{l}100(27 \cdot 5) \\
125(34 \cdot 4) \\
139(38 \cdot 2) \\
\end{array}$ & $\begin{array}{l}98(36 \cdot 8) \\
98(36 \cdot 8) \\
70(26.3) \\
\end{array}$ \\
\hline $\begin{array}{l}\text { Anastomotic leaks (\%) } \\
\text { Grade A } \\
\text { Grade B } \\
\text { Grade C } \\
\end{array}$ & $\begin{array}{c}64 / 583(11 \cdot 0) \\
5(0 \cdot 9) \\
38(6 \cdot 5) \\
21(3 \cdot 6) \\
\end{array}$ & $\begin{array}{c}19 / 364(5 \cdot 2) \\
- \\
5(1 \cdot 4) \\
14(3 \cdot 8) \\
\end{array}$ & $\begin{array}{c}83 / 947(8 \cdot 8) \\
5(0 \cdot 5) \\
43(4 \cdot 5) \\
35(3 \cdot 7) \\
\end{array}$ & 0.002 & $\begin{array}{c}19 / 364(5 \cdot 2) \\
- \\
5(1 \cdot 4) \\
14(3 \cdot 8) \\
\end{array}$ & $\begin{array}{l}- \\
- \\
- \\
-\end{array}$ \\
\hline $\begin{array}{l}\text { Neoadjuvant Treatment (\%) } \\
\text { Systemic chemotherapy } \\
\text { Radiotherapy } \\
\text { Short course radiotherapy } \\
\text { Long course chemoradiotherapy } \\
\text { Contact radiotherapy } \\
\end{array}$ & $\begin{array}{l}25(6.0) \\
131(22 \cdot 5) \\
35(6.0) \\
96(16.5) \\
0 \\
\end{array}$ & $\begin{array}{r}37(5.9) \\
168(26.7) \\
51(8.1) \\
116(18.4) \\
1(0.2) \\
\end{array}$ & $\begin{array}{r}72(5 \cdot 9) \\
299(24 \cdot 7) \\
86(7 \cdot 1) \\
212(17 \cdot 5) \\
1(0 \cdot 1) \\
\end{array}$ & $\begin{array}{l}0.211 \\
0.090 \\
0.156 \\
0.373 \\
0.336 \\
\end{array}$ & $\begin{array}{c}6(1 \cdot 7) \\
38(10 \cdot 4) \\
1(0 \cdot 3) \\
37(10 \cdot 2) \\
0 \\
\end{array}$ & $\begin{array}{c}31(11 \cdot 7) \\
130(48.9) \\
50(18.8) \\
79(29 \cdot 7) \\
1(0.4) \\
\end{array}$ \\
\hline $\begin{array}{l}\text { Adjuvant Treatment (\%) } \\
\text { Systemic chemotherapy } \\
\text { Radiotherapy }\end{array}$ & $\begin{array}{c}200(34 \cdot 4) \\
6(1 \cdot 0) \\
\end{array}$ & $\begin{array}{c}183(29.0) \\
10(1.6) \\
\end{array}$ & $\begin{array}{c}383 / 1213(31 \cdot 6) \\
16 / 1213(1 \cdot 3) \\
\end{array}$ & $\begin{array}{l}0.049 \\
0.395 \\
\end{array}$ & $\begin{array}{c}119(32 \cdot 7) \\
2(0 \cdot 6) \\
\end{array}$ & $\begin{array}{c}64 / 266(24 \cdot 1) \\
8 / 266(3 \cdot 0) \\
\end{array}$ \\
\hline
\end{tabular}

Table 1. Demographic data for patients undergoing diverting loop lleostomy versus comparison

cohorts not undergoing loop ileostomy. Demographic data for the whole population, and the two cohorts of patients stratified by presence or absence of ileostomy. For reference, the demographic data for the two subgroups of patients without ileostomy (HAR and APR) are also shown.

Figures in parentheses are percentages. TME: rectal resection with primary anastomosis and diverting ileostomy; HAR: rectal resection with primary anastomosis without diverting ileostomy; APR: abdominoperineal resection; eGFR: estimated glomerular filtration rate; CKD: chronic kidney disease; S.D.: standard deviation; ASA: American Society of Anaesthesiologists grade

\begin{tabular}{|c|c|c|c|c|c|c|}
\hline \multirow{2}{*}{ Procedure } & \multirow{2}{*}{ Time Point } & \multirow{2}{*}{ No CKD } & \multicolumn{4}{|c|}{ Moderate/ Severe CKD (CKD3+) } \\
\hline & & & CKD 3 & CKD 4 & CKD 5 & Total \\
\hline \multirow{3}{*}{ Ileostomy } & Preoperative (T0) & $503 / 581(86.6 \%)$ & $77 / 581(13.3 \%)$ & $1 / 581(0.2 \%)$ & 0 & 78/581 (13.4\%) \\
\hline & Postoperative (T1) & $433 / 562(77.0 \%)$ & $117 / 562(20.8 \%)$ & $12 / 562(2.1 \%)$ & 0 & $129 / 562(23.0 \%)$ \\
\hline & Postoperative (T2) & $379 / 529$ (71.6\%) & $126 / 529(23.8 \%)$ & $15 / 529(2.8 \%)$ & 9/529 (1.7\%) & $150 / 529(28.4 \%)$ \\
\hline \multirow{3}{*}{ No lleostomy } & Preoperative (T0) & $508 / 627(81.0 \%)$ & $111 / 627$ (17.7\%) & $7 / 627$ (1.1\%) & $1 / 627(0.2 \%)$ & 119/627 (19.0\%) \\
\hline & Postoperative (T1) & $406 / 497$ (81.7\%) & $86 / 497(17.3 \%)$ & $3 / 497$ (0.6\%) & $2 / 497$ (0.4\%) & $91 / 497(18.3 \%)$ \\
\hline & Postoperative (T2) & 411/555 (74.1\%) & $127 / 555$ (22.9\%) & $15 / 555$ (2.7\%) & 2/555 (0.4\%) & $144 / 555$ (25.9\%) \\
\hline
\end{tabular}

This article is protected by copyright. All rights reserved 
Table 2. Preoperative and postoperative rates of Chronic Kidney Disease (CKD) in ileostomy cohort and comparison cohort without ileostomy. Data show rates of patients fulfilling eGFR criteria for each of the CKD stages for the time point measured.

T0 is preoperatively before rectal resection; $\mathrm{T} 1$ is prior to ileostomy closure for ileostomy cohort or a matched time at six-months after rectal resection for comparison cohort without ileostomy; $\mathrm{T} 2$ is sixmonths after ileostomy closure or a matched time at twelve-months after rectal resection for comparison cohort without ileostomy. CKD stage was graded by Kidney Disease Improving Global Outcomes 2012 guidelines[30-32] [CKD stage 3 (CKD3) eGFR 30 to $<60 \mathrm{~mL}$.min.1.73m²; CKD4 15 to $<30 \mathrm{~mL}$.min.1.73m²; and CKD5 as $<15 \mathrm{~mL}$. min. $1.73 \mathrm{~m}^{2}$

This article is protected by copyright. All rights reserved 


\begin{tabular}{|c|c|c|c|c|c|c|}
\hline & $\begin{array}{c}\text { Univariate } \\
\text { Regression } \\
\text { Coefficient } \\
\text { (95\% confidence } \\
\text { interval) } \\
\\
n=1058\end{array}$ & $\mathbf{P}$ & $\begin{array}{c}\text { Multivariate } \\
\text { Regression } \\
\text { Coefficient } \\
\text { Discharge } \\
\text { Medications } \\
\text { Included } \\
\text { (95\% confidence } \\
\text { interval) } \\
\text { n=707 }\end{array}$ & $\mathbf{P}$ & $\begin{array}{c}\text { Multivariate } \\
\text { Regression } \\
\text { Coefficient } \\
\text { Discharge } \\
\text { Medications } \\
\text { Excluded } \\
\text { (95\% confidence } \\
\text { interval) } \\
\text { n=926 }\end{array}$ & $\mathbf{P}$ \\
\hline Age & $-0 \cdot 14(-0 \cdot 22$ to $-0 \cdot 07)$ & $<0.001$ & $-0 \cdot 37(-0 \cdot 49$ to $-0 \cdot 26)$ & $<0 \cdot 001$ & $-0 \cdot 35(-0 \cdot 44$ to $-0 \cdot 26)$ & $<0 \cdot 001$ \\
\hline Male sex & $-1 \cdot 20(-2 \cdot 72$ to $+0 \cdot 32)$ & $0 \cdot 121$ & $0 \cdot 65(-1 \cdot 17$ to $+2 \cdot 46)$ & $0 \cdot 486$ & $0 \cdot 30(-1 \cdot 29$ to $+1 \cdot 89)$ & $0 \cdot 716$ \\
\hline Preoperative eGFR & $-0 \cdot 13(-0 \cdot 17$ to $-0 \cdot 08)$ & $<0 \cdot 001$ & $-0 \cdot 28(-0 \cdot 34$ to $-0 \cdot 21)$ & $<0 \cdot 001$ & $-0 \cdot 24(-0 \cdot 30$ to $-0 \cdot 19)$ & $<0 \cdot 001$ \\
\hline $\begin{array}{l}\text { Loop Ileostomy } \\
\text { Formation }\end{array}$ & $-4 \cdot 83(-6 \cdot 28$ to $-3 \cdot 37)$ & $<0 \cdot 001$ & $-5 \cdot 34(-7 \cdot 12$ to $-3 \cdot 56)$ & $<0 \cdot 001$ & $-5 \cdot 00(-6 \cdot 53$ to $-3 \cdot 48)$ & $<0 \cdot 001$ \\
\hline $\begin{array}{l}\text { ASA Grade } \\
1 \\
2 \\
3 \\
4\end{array}$ & $\begin{array}{c}1(\text { reference }) \\
-3 \cdot 18(-5 \cdot 59 \text { to }-0 \cdot 76) \\
-4 \cdot 38(-7 \cdot 37 \text { to }-1 \cdot 39) \\
0 \cdot 74(-11 \cdot 6 \text { to }+13 \cdot 1)\end{array}$ & $0 \cdot 03$ & $\begin{array}{c}1 \text { (reference) } \\
-1 \cdot 38(-4 \cdot 05 \text { to }+1 \cdot 29) \\
-2 \cdot 22(-5 \cdot 74 \text { to }+1 \cdot 30) \\
0 \cdot 03(-16 \cdot 33 \text { to } \\
+16 \cdot 39)\end{array}$ & $0 \cdot 655$ & $\begin{array}{c}1 \text { (reference) } \\
-2 \cdot 10(-4 \cdot 38 \text { to }+0 \cdot 18) \\
-3 \cdot 05(-5 \cdot 93 \text { to }-0 \cdot 18) \\
-0 \cdot 47(-11 \cdot 9 \text { to }+11 \cdot 0)\end{array}$ & $0 \cdot 197$ \\
\hline $\begin{array}{l}\text { Tumour Dukes' stage } \\
\text { A [pT0-2 N0] } \\
\text { B [pT3-4 N0] } \\
\text { C [pT0-4 N1+] }\end{array}$ & $\begin{array}{c}1 \text { (reference) } \\
-0 \cdot 65(-2 \cdot 50 \text { to }+1 \cdot 21) \\
1 \cdot 46(-0 \cdot 34 \text { to }+3 \cdot 25)\end{array}$ & $0 \cdot 06$ & $\begin{array}{c}1 \text { (reference) } \\
-1 \cdot 74(-3 \cdot 92 \text { to }+0 \cdot 45) \\
0 \cdot 58(-2 \cdot 03 \text { to }+3 \cdot 19)\end{array}$ & $0 \cdot 125$ & $\begin{array}{c}1 \text { (reference) } \\
-0 \cdot 83(-2 \cdot 73 \text { to }+1 \cdot 07) \\
0 \cdot 04(-2 \cdot 25 \text { to }+2 \cdot 32)\end{array}$ & $0 \cdot 603$ \\
\hline Anastomotic leak & $-6 \cdot 62(-9 \cdot 57$ to $-3 \cdot 66)$ & $<0 \cdot 001$ & $-5 \cdot 40(-8 \cdot 74$ to $-2 \cdot 05)$ & $0 \cdot 002$ & $-5 \cdot 14(-8 \cdot 08$ to $-2 \cdot 20)$ & $0 \cdot 001$ \\
\hline $\begin{array}{l}\text { Discharge } \\
\text { Medications } \\
\text { Insulin/ } \\
\text { antihyperglyaemics }\end{array}$ & $-2 \cdot 00(-4 \cdot 14$ to $+0 \cdot 15)$ & $0 \cdot 068$ & $-1 \cdot 01(-3 \cdot 06$ to $1 \cdot 04)$ & $0 \cdot 334$ & - & - \\
\hline $\begin{array}{l}\text { Antihypertensives } \\
\text { NSAIDs } \\
\text { ACE/ AT2 inhibitors } \\
\text { PPIs }\end{array}$ & $\begin{array}{l}-1 \cdot 82(-3 \cdot 72 \text { to }+0 \cdot 08) \\
-1 \cdot 54(-3 \cdot 75 \text { to }+0 \cdot 67) \\
-2 \cdot 54(-4 \cdot 66 \text { to }-0 \cdot 42) \\
-0 \cdot 74(-2 \cdot 68 \text { to }+1 \cdot 20)\end{array}$ & $\begin{array}{l}0 \cdot 061 \\
0 \cdot 172 \\
0 \cdot 019 \\
0 \cdot 454\end{array}$ & $\begin{array}{c}1 \cdot 28(-1 \cdot 44 \text { to }+4 \cdot 01) \\
-0 \cdot 41(-2 \cdot 54 \text { to } 1 \cdot 72) \\
-3 \cdot 06(-6 \cdot 00 \text { to }-1 \cdot 25) \\
-\end{array}$ & $\begin{array}{c}0 \cdot 357 \\
0 \cdot 706 \\
0 \cdot 041 \\
-\end{array}$ & $\begin{array}{l}- \\
- \\
- \\
-\end{array}$ & $\begin{array}{l}- \\
- \\
-\end{array}$ \\
\hline $\begin{array}{l}\text { Neoadjuvant } \\
\text { Treatment (\%) } \\
\text { Radiotherapy (SCRT/ } \\
\text { LCCRT) } \\
\text { Systemic } \\
\text { chemotherapy }\end{array}$ & $\begin{array}{l}0 \cdot 46(-1 \cdot 24 \text { to }+2 \cdot 17) \\
-0 \cdot 50(-3 \cdot 61 \text { to }+2 \cdot 61)\end{array}$ & $\begin{array}{l}0 \cdot 594 \\
0 \cdot 752\end{array}$ & - & - & - & $\begin{array}{l}- \\
-\end{array}$ \\
\hline $\begin{array}{l}\text { Adjuvant Treatment } \\
(\%)\end{array}$ & & & & & & \\
\hline $\begin{array}{l}\text { Radiotherapy } \\
\text { Systemic } \\
\text { chemotherapy }\end{array}$ & $\begin{array}{l}2 \cdot 02(-4 \cdot 24 \text { to }+8 \cdot 29) \\
2 \cdot 55(+1 \cdot 00 \text { to }+4 \cdot 11)\end{array}$ & $\begin{array}{l}0.526 \\
0.001\end{array}$ & $1 \cdot 97(-0 \cdot 50$ to $+4 \cdot 43)$ & $\begin{array}{c}- \\
0 \cdot 117\end{array}$ & $1 \cdot 38(-0 \cdot 72$ to $+3 \cdot 48)$ & $\begin{array}{c}- \\
0 \cdot 197\end{array}$ \\
\hline
\end{tabular}

This article is protected by copyright. All rights reserved 
Table 3.

Univariate and multivariate regression analysis showing impact of patient and operative factors on absolute changes in postoperative renal function, comparing postoperative renal function $\left(T_{1}\right)$ with preoperative baseline at $T_{0}$.

eGFR: estimated glomerular filtration rate; ASA: American Society of Anaesthesiologists; NSAIDs: nonsteroidal anti-inflammatory drugs; ACE: angiotensin-converting enzyme; AT2: angiotensin-2; PPIs: protonpump inhibitors; SCRT: short-course radiotherapy; LCCRT: long-course chemoradiotherapy.

Figure 1. Distribution of timing of ileostomy closure.

Figure plots monthly number of ileostomy closures (Left axis and blue bars) and the cumulative closure rate (grey Kaplan-Meier curve and Right axis, vertical ticks- censor points).

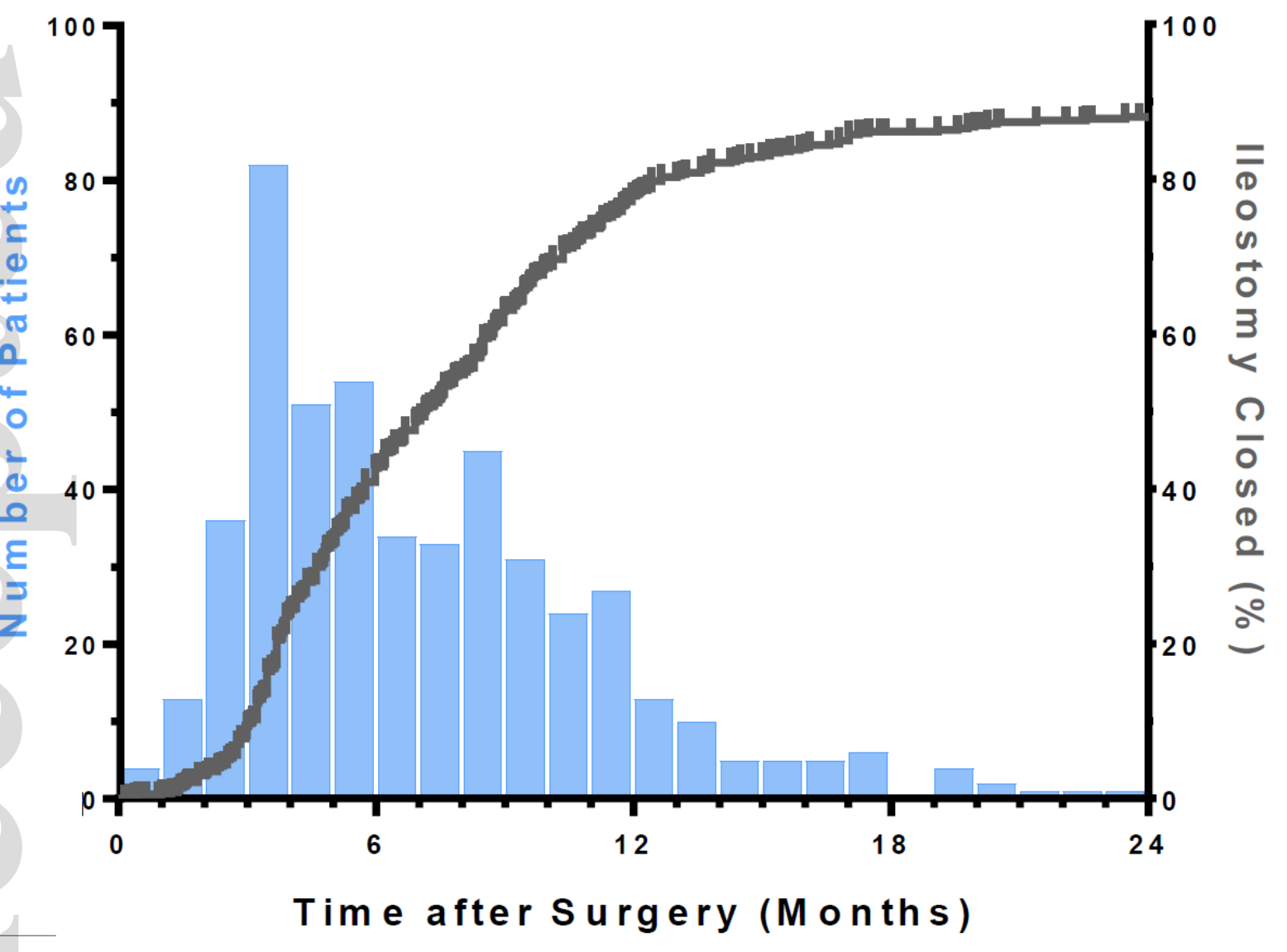

This article is protected by copyright. All rights reserved 